\title{
Interfacial Design for Joining Technologies: An Historical Perspective
}

\author{
J. Janczak-Rusch, G. Kaptay, and L.P.H. Jeurgens
}

(Submitted February 12, 2014; published online March 5, 2014)

\begin{abstract}
This paper gives an historic perspective of the concept of "Interfacial Design" in joined (e.g. soldered, brazed, diffusion bonded) assemblies. During the course of history, the awareness grew that the interface in a material joint can be perceived at different length scales. With the continuing development of joining materials and technologies, it became evident that the performance of assemblies is critically dependent on the structure and composition of the multiple internal interfaces in the material joints. Resulting trends in the microstructural design of soldering, brazing, and other bonding materials by smart engineering of internal interfaces, as driven by increasingly complex technological requirements, are briefly addressed.
\end{abstract}

Keywords brazing, coatings, interfaces, joining, nanomaterials

\section{Introduction}

Interfaces of multi-phase materials and their assemblies (e.g., hetero-interfaces, phase boundaries, grain boundaries, and free surfaces) impose dimensional and microstructural constrains to the mobility of atoms, single defects, dislocations, electrons, photons, phonons, and plasmons. Hence, the local atom arrangement, defect structure, and coherency strain at internal interfaces are decisive for tuning the functional (e.g., mechanical, electrical, magnetic, thermal, or optical) properties of components and devices: see Ref 1-5 and references therein. Particularly in nano-structured materials, such as thin film systems and nano-composites, a relatively large volume fraction of atoms is associated with internal interfaces, which often results in "unusual" materials properties, which are different from those of the corresponding bulk material(s): e.g., an ultra-high yield strength, superparamagnetism, high catalytic activity, size-dependent optical properties, and/or a strikingly lower (pre-melting) or higher (superheating) melting point (Ref 6).

In addition, in nano-structured materials, the excess energies associated with internal interfaces often dominate the energetics

This article is an invited submission to JMEP selected from presentations at the Symposia "Wetting," "Interface Design," and "Joining Technologies" belonging to the Topic "Joining and Interface Design" at the European Congress and Exhibition on Advanced Materials and Processes (EUROMAT 2013), held September 8-13, 2013, in in Sevilla, Spain, and has been expanded from the original presentation.

J. Janczak-Rusch and L.P.H. Jeurgens, Laboratory for Joining Technologies and Corrosion, Empa, Swiss Federal Laboratories for Materials Science and Technology, 8600 Dübendorf, Switzerland; and G. Kaptay, Bay Zoltan Nonprofit Ltd., 2 Igloi, 3519 Miskolc, Hungary; and University of Miskolc, Egyetemvaros, 3515 Miskolc, Hungary. Contact e-mail: jolanta.janczak@empa.ch. of the system: i.e., a high density of internal interfaces typically increases the total Gibbs energy of the system (Ref 7), thereby providing large driving forces for microstructural and interfacial transformations, such as interfacial segregation, wetting, complexion transition, reconstruction, intermixing and compound formation. In addition, the relatively short diffusion distances, often in combination with enhanced diffusion rates of atoms along internal interfaces, enable much faster kinetics for thermodynamic equilibration, which makes artificially, manmade nanostructured components and nano-devices very prone to degradation (Ref 8-10).

Evidently, tailoring the properties (including the chemical and mechanical stability) of internal interfaces is of cardinal importance in numerous technologies in the fields of, e.g., mechanical engineering, microelectronics, nano-photonics, catalysis, photovoltaics, and sensing devices.

In the field of traditional joining technologies (e.g., brazing, soldering, diffusion bonding), it has also long been recognized that the performance of a material joint critically depends on the microstructure of the "macroscopic" interface, as conceived by the brazed zone in between the parent joining materials. However, such a "macroscopic" perception disregards the presence of multiple internal interfaces, such as grain and phase boundaries, within the brazed zone, which actually govern the properties of the material joint. Until the present date, the concept of interfacial design (or interface engineering) at various length scales for tailoring the properties of a material joint is often still not envisioned as an integral and crucial part of joint manufacturing. Only in recent days, due to the continuing miniaturization of material components in modern nano-technologies (e.g. micro-electronics, medical implants, microelectromechanical systems and sensing devices), interfacial design is becoming a crucial task for integrating, packaging and assembling increasingly complex nano- and microscale materials and components at everlower temperatures (Ref 11). In particular, smart design (or engineering) of the local composition and structure of the internal interfaces in nano- and microscale systems is needed to allow faster and more reliable fabrication, continuing miniaturization, further cost reduction, and enhanced durability during service. 
With the aim to face the aforementioned technological challenge, the current authors initiated a first symposium on "Interfacial Design" within the "Joining" topic at the Euromat 2013 conference. The initiative follows similar trends in other conference series, such as the International Conference on Brazing, Diffusion Bonding and High Temperature Brazing, which also organized a first session on Nanotechnology in 2013. Noteworthy, a new conference series on the topic of Nano- and Microjoining has been initiated in 2012 with a forthcoming conference in 2014 (see www.nmj2014.org). These scientific progressions in the field of joining are strongly driven by the industrial demand to control the microstructure of a material joint with its internal interfaces down to the atomic scale. In the past, the development of new joining concepts typically succeeded the first development stages of material and system design, components manufacturing, and assembly. In more recent days, with the continuous miniaturization of functional components, the joining process is becoming more and more an integrative part of the product development and manufacturing chain (Ref 12).

\section{Interfaces in Material Joints: A Historical Perspective}

Joining is a very ancient technology; first soldering and brazing technologies are thought to date back to before 4000 BC. Back then as nowadays, the fabrication of a good joint could only be mastered by establishing a solid bond between the two material components. A main criterion for a good joint still is the strength of the chemical bond across the macro-interface. Some of the first objects manufactured by joining technologies in ancient history, such as jewelery or weapons, have lasted until today and can be admired in archeological museums worldwide. They evidence that, already in ancient times, humans mastered the joining of all kinds of dissimilar materials, such as metals, alloys, and glasses.

For a long time, a material joint was understood as a connection of two materials, separated by a single boundary plane with invisible or negligible thickness and without any specific properties. Soon after the invention of different solders and brazing filler metals (alloys), the awareness grew that the properties of a material joint can be controlled by smart selection of the type of the solder or brazing filler. As a result, increasing attention was paid to the resulting microstructure of the joined zone between the two base materials. From this time on, the microstructure and constituents of the macroscopic interface were studied in more detail. In the case of a brazed joint, the macro-interface of the joint involves a zone with a thickness of a few tenths of a millimeter, as constituted by the reacted brazing filler (the modified brazing filler alloy) in the center and its reaction zones with the base materials. Similar concepts were considered for material joints produced by other metallurgical bonding processes, such as soldering or diffusion bonding processes. Nevertheless, it was (and still is) often naively assumed that the interface, as defined by the brazing zone, possesses similar properties as those of the applied brazing filler. Furthermore, the quality of a joint was (and still is) often simply judged on the basis of the size and shape of visible defects and discontinuities in the brazing zone. Hence the procedure for the optimization of a given joining process

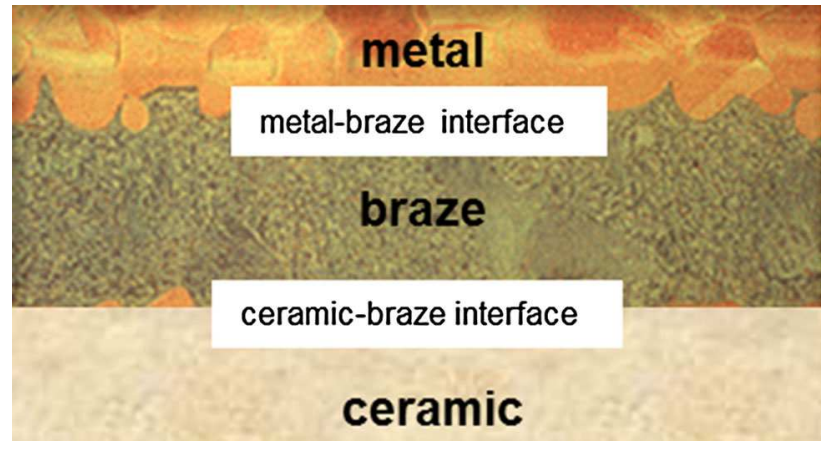

Fig. 1 An exemplary metal-ceramic joint: the "macro-interface" of the joint involves the zone with a thickness of a few tenths of a millimeter, as constituted by the reacted brazing filler (the modified brazing filler alloy) in the center and its reaction zones with the base materials. For metal-ceramic joints, the two "micro-interfaces" as associated with the opposite reaction zones have contrasting chemical bonding characteristics

often still proceeds by a series of trial-and-error joining experiments with a pre-selection of different brazing filler materials.

With the development of joints of dissimilar materials with very different electronic bonding configurations, such as metals and ceramics, the brazing community recognized that it is not sufficient to optimize only the applied brazing filler alloy and its resulting microstructure after joining. To optimize the properties of the material joint it became more and more essential to control the contrasting chemical reactions at the opposing micro-interfaces of the braze with the dissimilar base materials (see Fig. 1), as tailored by the addition of so-called (re-)active elements (e.g., $\mathrm{Ti}, \mathrm{Cr}$, and $\mathrm{Zr}$ ).

However, the quality of a brazed metal-ceramic joint not only relies on strong chemical bonding at the opposing microinterfaces and, consequently, a good wetting behavior of the brazing filler with the ceramic (Ref 13-16). The joint quality also critically depends on the residual stress levels in the brazed zone, as originating from the characteristically large difference in thermal expansion coefficients between the metal and the ceramic (Ref 17-21). Ideally the brazing filler should have a high plasticity and an intermediate (or even gradient) thermal expansion coefficient between the metal and the ceramic to prevent large stress gradients in the joint zone (Ref 21-24). Unfortunately, such ideal brazing fillers are not always available and then complex interface engineering is needed to deal with the large thermal expansion mismatch between the two base materials. Typical strategies to reduce the stress gradient in the metal-ceramic joint zone are the application of: (i) a combination of one or more brazing fillers with a reactive metallization layer(s) on the ceramic base material (Ref 25-28), (ii) a succession of interlayers with different thermal expansion coefficients to more gradually bridge the jump in thermal expansion coefficient between the metal and the ceramic base components (Ref 18, 29-31), (iii) composite brazing fillers (Ref 32-39).

Ceramic-particle-reinforced active brazing fillers are a typical example of the above mentioned composite brazing fillers for active brazing of metals to ceramics (Ref 17, 32, 40), see Fig. 2. Due to the increasing number of internal metalceramic interfaces induced upon addition of (micro-sized) ceramic particles to the active brazing filler (to tailor both the 
thermal expansion coefficient and the mechanical properties of the braze), high-quality joints can only be achieved by increasing the concentration of the active element (here: Ti) in the brazing filler with respect to the optimum content in the unreinforced brazing filler (Ref 17, 22, 41). Namely, the active element is needed to establish firm chemical bonding at all internal metal-ceramic interfaces, i.e., between the brazing filler and ceramic base material, as well as between the ceramic particles and the brazing filler matrix.

Also for metal-metal joints, such as lead-free soldering of $\mathrm{Cu}$ interconnects, it can be beneficial to add nano-sized metallic particles to the solder to improve the creep resistance (Ref 42-44) and to optimize the thermo-mechanical fatigue behavior of the interconnections (Ref 45, 46). For example, if $\mathrm{Cu}$ nanoparticles are added to a $\mathrm{Sn}-\mathrm{Ag}-\mathrm{Cu}$ solder when joining $\mathrm{Cu}$ components, the growth of the brittle $\mathrm{Cu}_{6} \mathrm{Sn}_{5}$ intermetallic

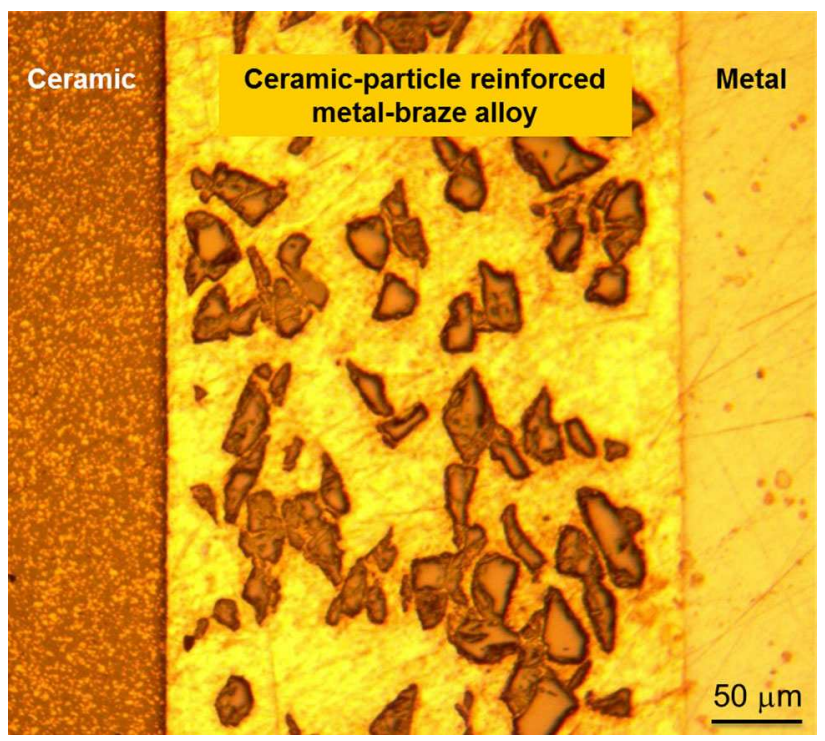

Fig. 2 Metal-ceramic joint (left $\mathrm{Si}_{3} \mathrm{~N}_{4} / \mathrm{TiN}$ ceramics, right $14 \mathrm{NiCr} 14$ steel), as produced by the application of a ceramic-particle-reinforced active brazing filler (center AgCuInTi reinforced with $\mathrm{SiC}$ particles) phase during joint service can be suppressed by the formation of the $\mathrm{Cu}_{6} \mathrm{Sn}_{5}$ around the $\mathrm{Cu}$ nano-particles, thus depleting $\mathrm{Sn}$ from the competing reaction with the $\mathrm{Cu}$ base material (Ref 45).

Another recent development in interfacial design for joining technologies is the research on the application of metallic nanomultilayers (NMLs) systems, e.g., reactive nanofoils as a potential local heat-source for the joining of heat-sensitive nano-structured materials and micro-scale devices (Ref 47-56), as applied in, e.g., microelectronics, packaging, sensors, and implantable medical devices. Reactive NMLs foils or coatings, constituted of alternating $\mathrm{Ni}-\mathrm{Al}$, Ti-Al, and Pd-Al sublayers with a thickness in the range of 3-100 nm, as prepared by conventional magnetron sputtering techniques, are among the most promising systems for such benign joining technologies. Thermal activation of the self-propagating chain of exothermic reactions associated with intermetallic phase formation in the NMLs results in the very fast release of thermal energy. Application of reactive NML foils or coatings between two base components thus enables instantaneously release of local heat in the vicinity of interface between the contacted base materials to establish a metallurgical joint, thereby restricting the heat-affected zone to a few hundreds of micrometers from the joint line.

Only very recently, a novel design of nanostructured brazing filler materials was proposed (Ref 57-70), which exploits nanoeffects, like fast interfacial reaction kinetics, grain boundary wetting, and melting point depression by nano-confinement to realize brazing at reduced temperatures (as compared to the brazing temperature for the corresponding bulk brazing alloy). Representative examples of such joining materials are brazing pastes from nanoparticles with an intelligent, temporary coating (Ref 71, 72), and nano-multilayers, constituted of alternating nanometer-thick layers of a brazing filler metal and a chemically inert barrier (e.g., a nitride, oxide or refractory metal) (Ref 69, 70) see Fig. 3. Evidently, such nano-effects are controlled by the local structure, chemical composition, and properties of the different internal interfaces. Hence interfacial design is a crucial first step in the development and application of such novel nano-structured joining materials. For example, the crucial role of the structure of internal interfaces on melting behavior was demonstrated for an In nano-particle in an Al

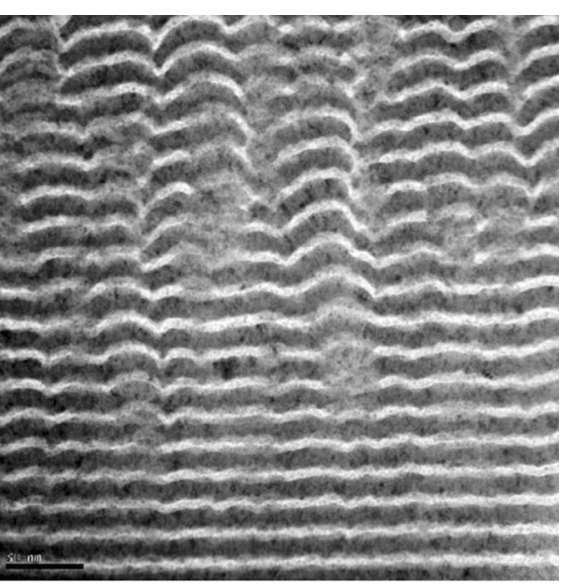

$\mathrm{Ag}-\mathrm{Cu} / \mathrm{C}$

Fig. 3 Nanomultilayers for joining: multiple internal interfaces between nanometer-thick layers of a typical braze alloy (Ag-Cu; dark) and a chemically inert barrier layer (AlN, C; bright) 


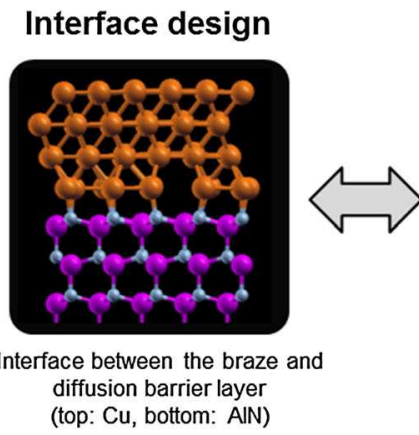

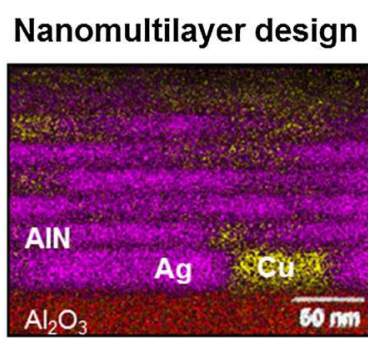

Internal and external interfaces in the nanomultilayer

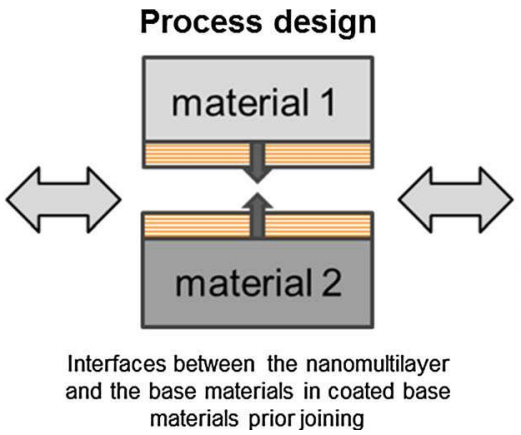

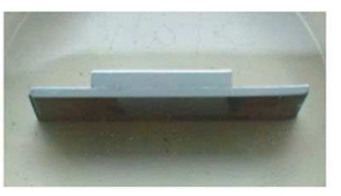

External and internal material interfaces at different length scales in the joint

Fig. 4 Illustration of the complex interplay between competing reactions at neighboring interfaces in nanostructured brazing fillers in a multilayer configuration

matrix; a coherent In-Al interface resulted in superheating, whereas a melting point depression occurred for the noncoherent In-Al interface (Ref 73). On this foundation (i.e., by smart interfacial design), strikingly large melting point depressions and very fast reaction kinetics can principally be achieved in a nanomultilayer configuration (Ref 70).

Some of the challenges which joining technologies are facing today (e.g., joining at low temperatures, while assuring operation of the joined assemblies at much higher temperatures) can only be mastered by exploring such new nano-scale-based concepts. Hence, a complex design of brazing filler metals and solders with a high density of smartly engineered internal interfaces is needed. Each internal interface will contribute to some extent to the physical and chemical properties (e.g., mechanic, thermal, electronic) of the material joint and hence principally should be tailored ("designed") to optimize and/or functionalize the joint assembly. Unfortunately, interfacial design down to the atomic scale is far from trivial, particularly due to the difficulties in controlling the kinetics of competing reactions (e.g., interdiffusion, intermixing, heterogeneous nucleation, and growth) at neighboring interfaces, as well as the developing stress gradients upon heating. For example, for the joining of base materials coated with nano-multilayers, the interface reactions in the nano-sized brazing filler (e.g., alloying, phase separation), those between the brazing filler and the barrier layer, as well as those between the brazing filler and the base materials, have to be controlled, see Fig. 4.

\section{Conclusions}

The concept of "Interface Design" in joining technologies has evolved during centuries and is still under discussion. During the course of history, the awareness grew that the interface in a material joint can be perceived at different length scales. With the continuing miniaturization of engineered components, it became more and more evident that the performance of material assemblies is critically dependent on the structure and composition of the multiple internal interfaces in the joint. Nowadays, a complex design of brazing filler metals and solders with a high density of smartly engineered internal interfaces is often needed to meet industrial requirements. The various interfaces in nanostructured joining materials offer us a new degree of freedom for optimization of the joining process. Each internal interface contributes to some extent to the physical and chemical properties (e.g., mechanic, thermal, electronic) of the material joint and therefore should be tailored ("designed") to optimize and/or functionalize the joint assembly. Unfortunately, such interface design down to the atomic scale is still far from trivial, particularly due to the difficulties in controlling the kinetics of competing reactions at neighboring interfaces and the developing stress gradients upon heating. The joining community has to face this big challenge. With this first symposium on Interface Design in Joining, controlling the structure and properties of interfaces in the joint should more and more become an integral part of advanced joining technologies.

\section{Acknowledgment}

We gratefully acknowledge the following colleagues for their scientific contributions to the examples illustrated in Figs. 2-4: A. Antusek, V. Bissig, G. Blugan, H.-R. Elsener, M. Galli, J. Kübler, M. Parlinska-Wojtan, D. Passerone, J. Patscheider, and G. Pigozzi. The financial support from COSTMP0903 Action and SBFI $\mathrm{Nr}$. C11.0055 project is greatly acknowledged. GK thanks the TÁMOP-4.2.1.B-10/2/KONV-2010-0001 project and the TÁMOP-4.2.2.A-11/1/KONV-2012-0019 project in the framework of the New Széchenyi Plan, supported by the European Union, and co-financed by the European Social Fund.

\section{References}

1. L.P.H. Jeurgens, Z. Wang, and E.J. Mittemeijer, Thermodynamics of Reactions and Phase Transformations at Interfaces and Surfaces, Int. J. Mater. Res., 2009, 100, p 1281-1307

2. J. Luo, Stabilization of Nanoscale Quasi-Liquid Interfacial Films in Inorganic Materials: A Review and Critical Assessment, Crit. Rev. Sol. State Mater. Sci., 2007, 2(1), p 67-109

3. G. Kaptay, Classification and General Derivation of Interfacial Forces, Acting on Phases, Situated in the Bulk, or at the Interface of Other Phases, J. Mater. Sci., 2005, 40, p 2125-2131

4. Y. Gao, A. Marconnet, M. Panzer, S. LeBlanc, S. Dogbe, Y. Ezzahri, A. Shakouri, and K.E. Goodson, Nanostructured Interfaces for Thermoelectrics, J. Electron. Mater, 2010, 39, p 1456-1462

5. Y. Zhu, Ch.-F. Tsai, and H. Wang, Atomic Interface Sequence, Misfit Strain Relaxation and Intrinsic Flux-Pinning Defects in Different $\mathrm{YBa}_{2} \mathrm{Cu}_{3} \mathrm{O}_{7-\delta}$ Heterogeneous Systems, Supercond. Sci. Technol, 2013, 26(2), p 025009

6. Q.S. Mei and K. Lu, Melting and Superheating of Crystalline Solids: From Bulk to Nanocrystals, Prog. Mater Sci., 2007, 52, p 1175-1262

7. G. Kaptay, Nano-Calphad: Extension of the Calphad Method to Systems with Nano-phases and Complexions, J. Mater. Sci., 2012, 47, p $8320-8335$ 
8. K.N. Tu, Interdiffusion in Thin Films, Ann. Rev. Mat. Sci., 1985, 15, p $147-176$

9. A.M. Gusak, T.V. Zaporozhets, Y.O. Lyashenko, S.V. Kornienko, M.O Pasichnyy, A.S. Shirinyan, Eds., Diffusion-controlled Solid State Reactions. Alloys, Thin Films and Nanosystems, Wiley, West Sussex, 2010, ISBN: 978-3-527-40884-9

10. R.W. Balluffi and J.M. Blakely, Special Aspects of Diffusion in ThinFilms, Thin Solid Films, 1975, 25(2), p 363-392

11. Y. Zhou, Ed., Microjoining and Nanojoining, CRC Press/Woodhead Publishing, Cambridge, 2008

12. S.S. Babu, S. Flowers, J. Janczak-Rusch, et al., Joining of Nanomaterials. GENNESYS White Paper, Max-Planck Gesellschaft, Munich, 2008

13. N. Eustathopoulos, M.G. Nicholas, and B. Drevet, Wettability at High Temperatures, Pergamon, Amsterdam, 1999

14. A. Passerone and M.L. Muolo, Metal-Ceramic Interfaces: Wetting and Joining Processes, Int. J. Mater. Prod. Technol., 2004, 20(5/6), p 420 439

15. J. Luo and Y.-M. Chiang, Wetting and Prewetting on Ceramic Surfaces, Annu. Rev. Mater. Res., 2008, 38, p 227-249

16. O.M. Akselsen, Advances in Brazing of Ceramics, J. Mater. Sci., 1992 , 27(8), p 1989-2000

17. J. Janczak-Rusch, Ceramic Component Integration by Advanced Brazing Technologies, Ceramic Integration and Joining Technologies. From Macro to Nanoscale, M. Singh, T. Ohji, R. Asthana, S. Mathur, Eds., Wiley, Chichester, 2011, ISBN: 978-0-470-39122-8

18. J.W. Park, P.F. Mendez, and T.W. Eagar, Strain Energy Distribution in Ceramic-to-Metal Joints, Acta Mater., 2002, 50, p 883-899

19. M. Galli, J. Botsis, J. Janczak-Rusch, G. Maier, and U. Welzel, Characterization of the Residual Stresses and Strength of CeramicMetal Braze Joints, J. Eng. Mater. Technol., 2009, 131, p 21004-1-8

20. M. Galli, J. Botsis, and J. Janczak-Rusch, Relief of the Residual Stresses in Ceramic-Metal Joints by a Layered Braze Structure, $A d v$ Eng. Mater, 2006, 8(3), p 197-201

21. A. Levy, Thermal Residual Stresses in Ceramic-to-Metal Brazed Joints, J. Am. Ceram. Soc., 1991, 74(9), p 2141-2147

22. V. Bissig, M. Galli, and J. Janczak-Rusch, Comparison of Three Different Active Filler Metals Used for Brazing Ceramic-to-Ceramic and Ceramic-to-Metal, Adv. Eng. Mater, 2006, 8(3), p 191-196

23. Y. Zhou, K. Ikeuchi, T.H. North, and Z. Wang, Effect of Plastic Deformation on Residual Stresses in Ceramic/Metal, Metall. Trans. A, 1991, 22, p 2822-2824

24. R.L. Williamson, B.H. Rabin, and J.T. Drake, Finite Element Analysis of Thermal Residual Stresses at Graded Ceramic-Metal Interfaces. Part I. Model Description and Geometrical Effects, J. Appl. Phys., 1993, 74, p 1310

25. V. Bissig, J. Janczak-Rusch, and M. Galli, Selection and Design of Brazing Fillers for Metal Ceramic Joints, Mater. Sci. Forum, 2007, 539-543, p 4008-4012

26. G. Blugan, J. Janczak-Rusch, and J. Kübler, Properties and Fractography of $\mathrm{Si}_{3} \mathrm{~N}_{4} / \mathrm{TiN}$ Ceramic Joined to Steel with Active Single Layer and Double Layer Braze Filler Alloys, Acta Mater., 2004, 52, p 4579 4588

27. G.B. Lin and J.H. Huang, Brazed Joints of $\mathrm{C}_{\mathrm{f}} / \mathrm{SiC}$ Composite to $\mathrm{Ti}$ Alloy Using Ag-Cu-Ti-(Ti+C) Mixed Powder as Interlayer, Powder Metall., 2006, 49, p 345-348

28. J. Lemus and R.A.L. Drew, Joining of Silicon Nitride with a Titanium Foil Interlayer, Mater. Sci. Eng., A, 2003, 352, p 169-178

29. C.G. Zhang, G.J. Qiao, and Z.H. Jin, Active Brazing of Pure Alumina to Kovar Alloy based on the Partial Transient Liquid Phase (PTLP) Technique with Ni-Ti Interlayer, J. Eur. Ceram. Soc., 2002, 22, p 2181-2186

30. G.W. Liu, F. Valenza, M.L. Muolo, and A. Passerone, SiC/SiC and SiC/Kovar Joining by Ni-Si and Mo Interlayers, J. Mater. Sci., 2010, 45, p 4299-4307

31. J.W. Park and T.W. Eagar, Strain Energy Release in Ceramic-to-metal Joints with Patterned Interlayers, Scripta Mater, 2004, 50, p 555-559

32. G. Blugan, J. Kuebler, V. Bissig, and J. Janczak-Rusch, Brazing of Silicon Nitride Ceramic Composite to Steel Using SiC-particlereinforced Active Brazing Alloy, Ceram. Int., 2007, 33, p 1033-1039

33. M. Galli, J. Botsis, and J. Janczak-Rusch, An Elastoplastic ThreeDimensional Homogenization Model for Particle Reinforced Composites, Comput. Mater., 2008, 41, p 312-321
34. G.B. Lin, J.H. Huang, and H. Zhang, Joints of Carbon Fiber-reinforced $\mathrm{SiC}$ Composites to Ti-alloy Brazed by Ag-Cu-Ti Short Carbon Fibers, J. Mater. Process. Tecnol., 2007, 189, p 25-261

35. Y.B. Chen, D.J. Liu, L.Q. Li, and F.Q. Li, Microstructure Evolution of Single Crystal $\mathrm{WC}_{\mathrm{p}}$ Reinforced Ti-6Al-4V Metal Matrix Composites Produced at Different Cooling Rates, J. Alloys. Compd., 2009, 484, p 108-112

36. Y.M. He, J. Zhang, C.F. Liu, and Y. Sun, Microstructure and Mechanical Properties of $\mathrm{Si}_{3} \mathrm{~N}_{4} / \mathrm{Si}_{3} \mathrm{~N}_{4}$ Joint Brazed with $\mathrm{Ag}-\mathrm{Cu}-$ $\mathrm{Ti}+\mathrm{SiC}_{\mathrm{p}}$ Composite Filler, Mater. Sci. Eng., A, 2010, 527, p 2819-2825

37. J.G. Yang, H.Y. Fang, and $\mathrm{X}$. Wan, $\mathrm{Al}_{2} \mathrm{O}_{3} / \mathrm{Al}_{2} \mathrm{O}_{3}$ Joint Brazed with $\mathrm{Al}_{2} \mathrm{O}_{3}$-Particulate-Contained Composite Ag-Cu-Ti Filler Material, J. Mater. Sci. Technol., 2005, 21, p 782-784

38. M.X. Yang, T.S. Lin, and P. He, $\mathrm{Cu}+\mathrm{TiB}_{2}$ Composite Filler for Brazing $\mathrm{Al}_{2} \mathrm{O}_{3}$ and Ti-6Al-4V Alloy, J. Alloys. Compd., 2012, 512, p 282-289

39. M.G. Zhu and D.D.L. Chung, Improving the Strength of Brazed Joints to Alumina by Adding Carbon Fibres, J. Mater. Sci., 1997, 32, p 53215333

40. M. Galli, J. Cugnoni, J. Botsis, and J. Janczak-Rusch, Identification of the Matrix Elastoplastic Properties in Reinforced Active Brazing Alloys, Comput. A, 2008, 39, p 972-978

41. M. Galli, J. Janczak-Rusch, and M. Szankowska, Influence of Ti on the Mechanical Properties of AgCuInTi Active Brazing Fillers, Adv. Eng. Mater., 2009, 11(1-2), p 71-74

42. F. Guo, J. Lee, J.P. Lucas, K.N. Subramanian, and T.R. Bieler, Creep Properties of Eutectic Sn-3.5Ag Solder Joints Reinforced with Mechanically Incorporated Ni Particles, J. Electron. Mater., 2001, 30(9), p 1222-1227

43. J.P. Liu, F. Guo, Y.F. Yan, W.B. Wang, and Y.W. Shi, Development of Creep-Resistant, Nanosized Ag Particle-Reinforced Sn-Pb Composite Solders, J. Mater. Sci., 2004, 33(9), p 958-963

44. A. Lee and K.N. Subramanian, Development of Nano-Composite Lead-Free Electronic Solders, J. Electron. Mater., 2005, 34(11), p 1399-1407

45. V. Sivasubramaniam, N. Bosco, J. Janczak-Rusch, J. Cugnoni, and J. Botsis, Interfacial Intermetallic Growth and Strength of Composite Lead-Free Solder Alloy Through Isothermal Aging, J. Electron. Mater., 2008, 37(10), p 1598-1604

46. V. Sivasubramaniam, M. Galli, J. Cugnoni, J. Janczak-Rusch, and J. Botsis, A study of the Shear Response of Lead-Free Composite Solder by Experimental and Homogenization techniques, J. Electron. Mater., 2009, 38(10), p 2122-2131

47. J. Wang, E. Besnoin, A. Duckham, S.J. Spey, M.E. Reiss, O.M. Knio, and T.P. Weihs, Joining of Stainless-Steel Specimens with Nanostructured Al/Ni Foils, J. Appl. Phys., 2004, 95(1), p 248-256

48. J. Wang, E. Besnoin, A. Duckham, S.J. Spey, M. Reiss, O.M. Knio, M. Powers, M. Whitener, and T.P. Weihs, Room-Temperature Soldering with Nanostructured Foils, Appl. Phys. Lett., 2003, 83(10), p 39873989

49. Y.T. Cheng, L. Lin, and K. Najafi, Localized Silicon Fusion and Eutectic Bonding for MEMS Fabrication and Packaging, J. MEMS, 2000, 9(1), p 3-8

50. H. Yang, M. Wu, and W. Fang, Localized Induction Heating Solder Bonding for Wafer Level MEMS Packaging, J. Micromech. Microeng., 2005, 15(2), p 394-399

51. R.W. Bower, M.S. Ismail, and B.E. Roberds, Low Temperature $\mathrm{Si}_{3} \mathrm{~N}_{4}$ Direct Bonding, Appl. Phys. Lett., 1993, 62(26), p 3485-3487

52. A.J. Swisto, E. Besnoin, A. Duckham, O.M. Knio, T.P. Weihs, and T.C. Hufnagel, Thermal and Microstructural Effects of Welding Metallic Glasses by Self-Propagating Reactions in Multilayer Foils, Acta Mater, 2005, 53(13), p 3713-3719

53. J. Bräuer, J. Besser, E. Tomoscheit, D. Klimm, S. Anbumani, M. Wiemer, and T. Gessner, Investigation of Different Nanoscale Energetic Material Systems for Reactive Wafer Bonding, ECS Trans., 2013, 50(7), p 241-251

54. R. Longtin, E. Hack, J. Neuenschwander, and J. Janczak-Rusch, Benign Joining of Ultrafine Grained Aerospace Aluminum Alloys Using Nanotechnology, Adv. Mater, 2011, 20, p 1-5

55. S. Simões, F. Viana, and M.F. Vieira, Reactive Commercial Ni/Al Nanolayers for Joining Lightweight Alloys, JMEP, 2014, doi: 10.1007/s11665-014-0923-x

56. A.J. Cavaleiro, A.S. Ramos, F.F. Braz, N. Schell, and M.T. Vieira, In Situ Characterization of NiTi/Ti6Al4V Joints During Reaction-Assisted 
Diffusion Bonding using Ni/Ti Multilayers, JMEP, 2014, doi:10.1007/ s11665-014-0930-y

57. E. Ide, A. Angata, A. Hirose, and K.F. Kobayashi, Metal-Metal Bonding Using Ag Metallo-organic Nanoparticles, Acta Mater., 2005, 53(8), p 2385-2393

58. Y. Akada, H. Tatsumi, T. Yamaguchi, A. Hirose, T. Morita, and E. Ide, Interfacial Bonding Mechanism Using Silver Metallo-Organic Nanoparticles to Bulk Metals and Observation of Sintering Behavior, Mater. Trans., 2008, 49, p 1537-1545

59. D. Wakuda, K.S. Kim, and K. Suganuma, Room Temperature Sintering of Ag Nanoparticles by Drying Solvent, Scripta Mater., 2008, 59(6), p 649-652

60. A. Hu, J.Y. Guo, H. Alarifi, G. Patane, Y.N. Zhou, G. Compagnini, and C.X. Xu, Low Temperature Sintering of Ag Nanoparticles for Flexible Electronics Packaging, Appl. Phys. Lett., 2010, 97, p 153117

61. M. Maruyama, R. Matsubayashi, H. Iwakuro, S. Isoda, and T. Komatsu, Silver Nanosintering: A Lead-Free Alternative to Soldering, Appl. Phys. A, 2008, 93, p 467-470

62. A. Oestreicher, T. Röhrich, J. Wilden, M. Lerch, A. Jakob, and Heinrich. Lang, An Innovative Method for Joining Materials at Low Temperature Using Silver (nano)Particles Derived From $\left[\mathrm{AgO}_{2} \mathrm{C}(-\right.$ $\left.\left.\mathrm{CH}_{2} \mathrm{OCH}_{2}\right)_{3} \mathrm{H}\right]$, Appl. Surf. Sci., 2013, 265, p 239-244

63. H. Alarifi, A. Hu, M. Yavuz, and Y.N. Zhou, Silver Nanoparticle Paste for Low-Temperature Bonding of Copper, J. Electron. Mater, 2011, 40, p 1394-1402

64. S. Jang, Y. Seo, J. Choi, T. Kim, J. Cho, S. Kim, and D. Kim, Sintering of Inkjet Printed Copper Nanoparticles for Flexible Electronics, Scripta Mater., 2010, 62(5), p 258-261
65. Ch. Zou, Y.L. Gao, B. Yang, X.Z. Xia, Q.J. Zhai, C. Andersson, and J. Liu, Nanoparticles of the Lead-free Solder Alloy Sn-3.0Ag-0.5Cu with Large Melting Temperature Depression, J. Electron. Mater., 2009, 38(2), p 351-355

66. T. Takahashi, S. Kamatsu, H. Nishikawa, and T. Takemoto, Thin film joining for high-temperature performance of power semi-conductor devices, Microelectron. Reliab., 2010, 50, p 220-227

67. M. Türpe, J. Janczak-Rusch, B. Grünenwald, and V. Bissig, Approach For Al Brazing With Nanofiller Metals, DVS-Berichte, Vol 289, Deutscher Verlag für Schweisstechnik, Düsseldorf, 2012, p 125-129

68. M. Türpe, P. Englert, J. Janczak-Rusch, V. Bissig, Patent DE $10,2008,050,433.5,2008$

69. G. Pigozzi, A. Antusek, J. Janczak-Rusch, M. Parlinska-Wojtan, D. Passerone, C.A. Pignedoli, V. Bissig, J. Patscheider, and L.P.H. Jeurgens, Phase Constitution and Interface Structure of Nano-sized Ag$\mathrm{Cu} / \mathrm{AlN}$ Multilayers: Experimental and Ab Initio Modeling, Appl. Phys. Lett., 2012, 101, p 181602

70. G. Kaptay, J. Janczak-Rusch, G. Pigozzi, and L.P.H. Jeurgens, Theoretical Analysis of Melting Point Depression of Pure Metals in Different Initial Configurations, JMEP, 2014, doi:10.1007/s11665014-0885-z

71. N.S. Bosco, B.A. Manhat, and J. Janczak-Rusch, Sacrificial Passivation of Nanoscale Silver Particles, Scripta Mater, 2008, 58, p 858-861

72. J. Yan, G. Zou, A. Hu, and Y.N. Zhou, Preparation of PVP Coated Cu NPs and its Applications for Low-Temperature Bonding, J. Mater. Chem., 2011, 21, p 15981-15986

73. K. Lu and Z.H. Jin, Melting and Superheating of Low-Dimensional Materials, Curr. Opin. Solid State Mater. Sci., 2001, 5, p 39-44 